\title{
Preparation of lyophilized recombinant prion protein for TSE diagnosis by RT-QulC
}

\author{
Soyoun Hwang, Trudy Tatum, Semakaleng Lebepe-Mazur and Eric M. Nicholson* (10)
}

\begin{abstract}
Objective: Transmissible spongiform encephalopathies (TSEs) are a group of fatal neurodegenerative diseases, often referred as prion diseases. TSEs result from the misfolding of the cellular prion protein ( $\operatorname{PrP} \mathrm{P}^{\mathrm{C}}$ ) into a pathogenic form $\left(\mathrm{PrP}^{\mathrm{SC}}\right)$ that accumulates in the brain and lymphatic tissue. Amplification based assays such as real-time quaking induced conversion allow us to assess the conversion of $\operatorname{PrPC}^{\mathrm{C}}$ to $\operatorname{PrP}^{\mathrm{SC}}$. Real-time quaking induced conversion (RTQuIC) can be used for the detection of PrPSc in a variety of biological tissues from humans and animals. However, RTQulC requires a continuous supply of freshly purified prion protein and this necessity is not sustainable in a diagnostic laboratory setting.
\end{abstract}

Results: In this study, we developed a method to dry and preserve the prion protein for long term storage allowing for production of the protein and storage for extended time prior to use and room temperature shipping to appropriate diagnostic laboratory destinations facilitating widespread use of RT-QuIC as a diagnostic method.

Keywords: PrP, Scrapie, TSE, Transmissible spongiform encephalopathy, RT-QulC, Lyophilize, Real time quaking induced conversion

\section{Introduction}

Prion diseases are a group of fatal neurologic diseases that result from the misfolding of the monomeric, cellular prion protein $\left(\mathrm{PrP}^{\mathrm{C}}\right)$ into an oligomeric, pathogenic form $\left(\mathrm{PrP}^{\mathrm{Sc}}\right)$. These diseases are also referred to as transmissible spongiform encephalopathies (TSEs) and include bovine spongiform encephalopathy (BSE) in cattle, scrapie in sheep and goat, chronic wasting disease (CWD) in deer and elk, and Creutzfeldt-Jakob disease (CJD), fatal familial insomnia, Gerstmann-Sträussler-Scheinker syndrome, and kuru in humans. $\operatorname{PrP}^{\mathrm{Sc}}$ accumulates in the central nervous system in all TSEs, and in cases of scrapie in sheep and CWD in cervids, $\mathrm{PrP}^{\mathrm{Sc}}$ also accumulates in the lymphoid tissues [1-3].

At present, approved TSE diagnostic tests are all based upon direct detection of $\mathrm{PrP}^{\mathrm{Sc}}$ using the antibody based approaches immunoblot, enzyme immunoassay (EIA or ELISA), and immunohistochemistry $[4,5]$. However, new

\footnotetext{
*Correspondence: Eric.Nicholson@ars.usda.gov

Virus and Prion Research Unit, National Animal Disease Center, United States Department of Agriculture, Agricultural Research Service, Ames, IA 50010, USA
}

prion detection tools such as protein misfolding cyclic amplification (PMCA) [6-8] and the real-time quakinginduced conversion (RT-QuIC) assay have gained notoriety in TSE diagnostics based on the high sensitivity afforded by in vitro amplification of $\mathrm{PrP}^{\mathrm{Sc}}$ [9-11]. While PMCA and RT-QuIC differ in the substrate utilized and the approach to enhance the in vitro conversion, both report on the presence of $\mathrm{PrP}^{\mathrm{Sc}}$ in a sample through conversion where $\mathrm{PrP}^{\mathrm{Sc}}$ present in the diagnostic sample acts as a seed to initiate conversion of the provided substrate from a monomeric prion protein to an oligomeric form. RT-QuIC uses bacterially expressed, purified recombinant prion protein $(\mathrm{rPrP})$ and controlled shaking. A steady supply of high quality purified $\mathrm{rPrP}$ is required. This is generally accomplished by utilizing one of the proven methods of expression based on the expression of $\mathrm{rPrP}$ in inclusion bodies and purification using metal ion affinity column chromatography. Bank vole (BV) $r P r P$ has been shown to be a universal substrate for the amplification of $\mathrm{PrP}^{\mathrm{Sc}}$ from a variety of different TSEs and host species [12, 13]. Classical sheep scrapie, atypical Nor 98 sheep scrapie, classical BSE, H-type BSE, CWD from elk

(c) This is a U.S. Government work and not under copyright protection in the US; foreign copyright protection may apply 2018. This article is distributed under the terms of the Creative Commons Attribution 4.0 International License (http://creativeco mmons.org/licenses/by/4.0/), which permits unrestricted use, distribution, and reproduction in any medium, provided you give appropriate credit to the original author(s) and the source, provide a link to the Creative Commons license, and indicate if changes were made. The Creative Commons Public Domain Dedication waiver (http://creativecommons.org/publicdomain/ zero/1.0/) applies to the data made available in this article, unless otherwise stated. 
and deer, hamster, mouse and human samples including sCJD type 1, sCJD type 2, vCJD and iCJD have been detected with BV rPrP in RT-QuIC [14].

Lyophilized protein powders offer advantages over aqueous preparations of protein with regard to storage, shipping, and shelf-life. While there are purification approaches for $\mathrm{rPrP}$ available in the literature that include a lyophilization step, the resolubilization step generally involves high concentrations of denaturation and subsequent refolding of the protein [15-18]. Here, we present an approach to prepare lyophilized rPrP suitable for RT-QuIC based detection of $\mathrm{PrP}^{\mathrm{Sc}}$.

\section{Main text \\ Methods \\ Brain homogenate preparations}

Brain homogenates $(10 \% \mathrm{w} / \mathrm{v})$ in 1X PBS (Dulbecco's PBS, pH 7.4, lacking calcium and magnesium) were prepared from archived tissue available from previously published studies that have been stored at $-80^{\circ} \mathrm{C}[19,20]$.

\section{Protein production}

E. coli (BL21(入DE3)) was transformed with the pET28a vector containing the bank vole PRNP gene (amino acids 23-231; GenBank accession number AF367624) and the recombinant bank vole prion protein ( $\mathrm{BV} r \mathrm{PrP})$ was expressed and purified as previously described for the bovine prion protein with slight modification [21]. Briefly, E. coli strains (BL21( $\lambda \mathrm{DE} 3)$ ) containing the bank vole were grown and BV rPrP was expressed in the Overnight Express Autoinduction system (EMD Biosciences). Then cultures were harvested, and the cell pellet (3-4 g) was suspended and lysed to isolate the inclusion bodies. BV rPrP was purified with Ni-NTA (Nickel) resin (Qiagen, \#30210) and individual fractions were analyzed by SDS-PAGE. All eluted pooled fractions were dialyzed in $10 \mathrm{mM}$ potassium phosphate $(\mathrm{pH} 7.0)$ and lyophilized and stored at $-20^{\circ} \mathrm{C}$. Prior to use, BV rPrP was resolubilized in the double distilled water and used immediately. The concentration of pooled protein eluent or resolubilized lyophilized protein was measured by UV spectroscopy and calculated from the absorbance at $280 \mathrm{~nm}$ using an extinction coefficient of $62005 \mathrm{M}^{-1} \mathrm{~cm}^{-1}$ as calculated for BV protein (23-231) and the final products were compared.

\section{RT-QuIC}

RT-QuIC reactions were performed as previously described [14, 22-27]. The reaction mix was composed of $10 \mathrm{mM}$ phosphate buffer (pH 7.4), $100 \mathrm{mM}$ to $500 \mathrm{mM}$ $\mathrm{NaCl}, 0.1 \mathrm{mg} / \mathrm{ml}$ freshly prepared or lyophilized and resolubilized BV $\mathrm{rPrP}, 10 \mu \mathrm{M}$ thioflavin $\mathrm{T}$ (ThT), and $1 \mathrm{mM}$ ethylenediaminetetraacetic acid tetrasodium salt.
Aliquots of the reaction mix $(98 \mu \mathrm{L})$ were loaded into each well of a black 96-well plate with a clear bottom (Nunc, Thermo Fisher Scientific) and seeded with $2 \mu \mathrm{L}$ of clinical samples, either known scrapie positive or negative control brain homogenate dilutions. The plate was then sealed with plate sealer film and incubated at $42{ }^{\circ} \mathrm{C}$ in a BMG FLUOstar Omega plate reader with cycles of 1 min shaking (700 rpm double orbital) and 1 min rest for $100 \mathrm{~h}$. ThT fluorescence measurements (excitation, $460 \mathrm{~nm}$; emission $480 \mathrm{~nm}$, bottom read, 20 flashes per well, manual gain 1400) were taken every $15 \mathrm{~min}$. All reactions for each dilution and each sample were performed in 2 repeats of 4 replicates for a total of 8 RTQuIC assays. ThT fluorescence data are displayed as the average ThT fluorescence of four technical replicates for each time point and, to be considered positive, the ThT fluorescence of at least two replicate reactions must be positive. As previously described for classification of positive samples by RT-QuIC, the positive threshold was calculated as the mean value of non-inoculated control sheep brain homogenates plus 10 standard deviations $[22,28,29]$.

\section{Secondary structure and stability evaluation by Far-UV circular dichroism spectroscopy}

Far UV circular dichroism (CD) spectra were recorded on a Jasco J-815 spectropolarimeter equipped with a temperature control. Spectra were recorded by averaging three scans in the $200-260 \mathrm{~nm}$ range at a scan rate of $10 \mathrm{~nm} / \mathrm{min}$. Spectra were acquired at a protein concentration of $2-3 \mu \mathrm{M}$ of freshly prepared or lyophilized and resolubilized $\mathrm{BV}$ protein using $1 \mathrm{~cm}$ path length cell to verify if lyophilized $\operatorname{PrP}$ is correctly folded compared to freshly prepared BV rPrP. Thermal denaturation curves were monitored by $\mathrm{CD}$ at $222 \mathrm{~nm}$ over the temperature range of $20-85{ }^{\circ} \mathrm{C}$. The heating rate in all experiments was $1{ }^{\circ} \mathrm{C} / \mathrm{min}$. $\mathrm{CD}$ signals were plotted as a function of temperature and fit to determine the temperature of unfolding [30].

\section{Results}

\section{Protein recovery after lyophilization and resolubilization}

In order to investigate protein loss due to the lyophilization and resolubilization, following purification and refolded $\mathrm{BV} \mathrm{rPrP}$ in $10 \mathrm{mM}$ potassium phosphate $\mathrm{pH}$ 7.0 was lyophilized. Following lyophilization the protein was then resolubilized in a volume of distilled water equivalent to the total volume of protein solution prior to lyophilization. Based upon the absorbance at $280 \mathrm{~nm}$ and the extinction coefficient of $62005 \mathrm{M}^{-1} \mathrm{~cm}^{-1}$ it was determined that protein recovery following lyophilization and resolubilization was greater than $95 \%$. As 
expected, the apparent molecular weight as determined by SDS-PAGE was not affected by the lyophilization process indicating that there was no fragmentation or degradation (Fig. 1).

\section{Secondary structure and thermal denaturation of $B V r P r P$ with and without lyophilization}

In order to investigate whether lyophilization influenced the folding or stability, BV rPrP was analyzed with regard to secondary structure and thermal denaturation. Characteristic minima at $208 \mathrm{~nm}$ and $222 \mathrm{~nm}$ were observed in the far-UV CD spectra demonstrated with the spectra of the lyophilized BV rPrP essentially indistinguishable to

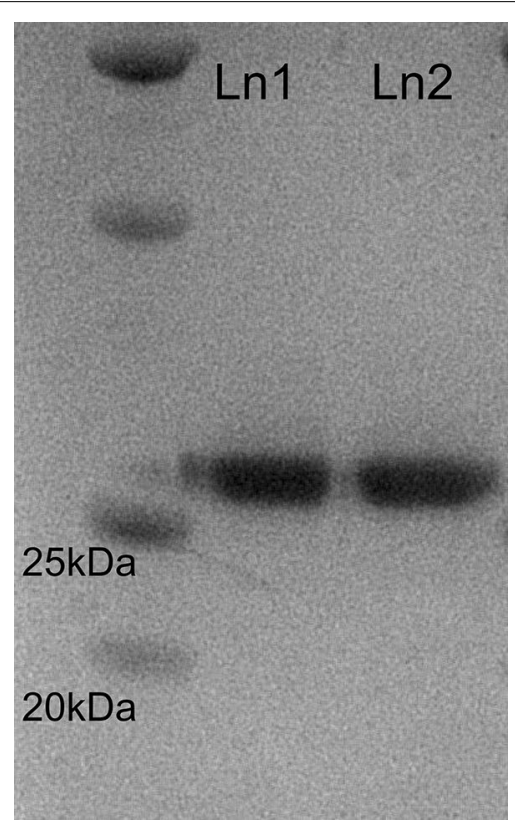

Fig. 1 SDS-PAGE for purified BV rPrP. Lane 1: purified BV rPrP protein solution, Lane 2: Lyophilized and resolubilized BV rPrP that of the freshly prepared protein (Fig. 2a). In addition, thermal denaturation curves of lyophilized and freshly prepared BV protein were measured to establish any changes in the cooperative folding that resulted from the lyophilization and resolubilization. The thermal unfolding was cooperative for both preparations and the midpoint for BV rPrP was $65.3 \pm 0.3^{\circ} \mathrm{C}$ with and $64.4 \pm 0.5^{\circ} \mathrm{C}$ without the lyophilization and resolubilization steps (Fig. 2b).

\section{Lyophilized BV rPrP is suitable for RT-QuIC based detection of PrPsc}

To evaluate whether lyophilized BV protein can be used as a substrate for RT-QuIC reactions, assays containing lyophilized or freshly prepared recombinant BV protein were seeded with dilutions of a $10 \%(\mathrm{w} / \mathrm{v})$ brain homogenate from 2 different scrapie positive sheep (Fig. 3a, b, d, e) or a confirmed negative control (Fig. 3c, d). Assays utilizing lyophilized BV substrate showed fibril formation with all brain dilutions $10^{-3}, 10^{-4}$, and $10^{-5}$ as freshly prepared BV substrate showed similar seeding activity for a given animal regardless of whether the substrate was freshly prepared or lyophilized and resolubilized. Neither substrate produced fibril when seeded with brain homogenate from a non-inoculated control based on the absence of an increase in ThT fluorescence (Fig. 3c, f).

\section{Discussion and conclusions}

With this study, we provide proof of concept that lyophilized BV rPrP can be utilized for RT-QuIC reactions based on detection of $\mathrm{PrP}^{\mathrm{Sc}}$ with lyophilized and resolubilized BV rPrP substrate. Overall, the lyophilization and resolubilization step results in minimal loss in protein, an absence of an appreciable change in secondary structure or temperature of unfolding, and RT-QuIC results of comparable sensitivity to freshly prepared protein.
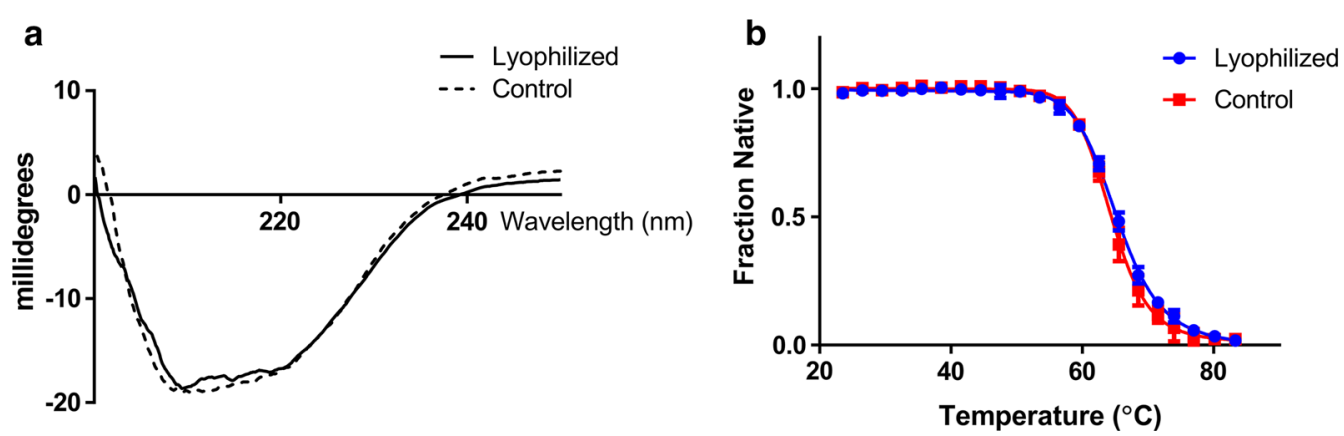

Fig. 2 Circular dichroism characterization of freshly prepared and resolubilized BV rPrP. a Far-UV circular dichroism spectra of freshly prepared (dotted line) and lyophilized and resolubilized (line) BV rPrP (23-231) and $\mathbf{b}$ thermal unfolding curves for lyophilized and resolubilized (red) and freshly prepared (blue) BV rPrP in $10 \mathrm{mM}$ phosphate buffer, $\mathrm{pH} 7.0$ 

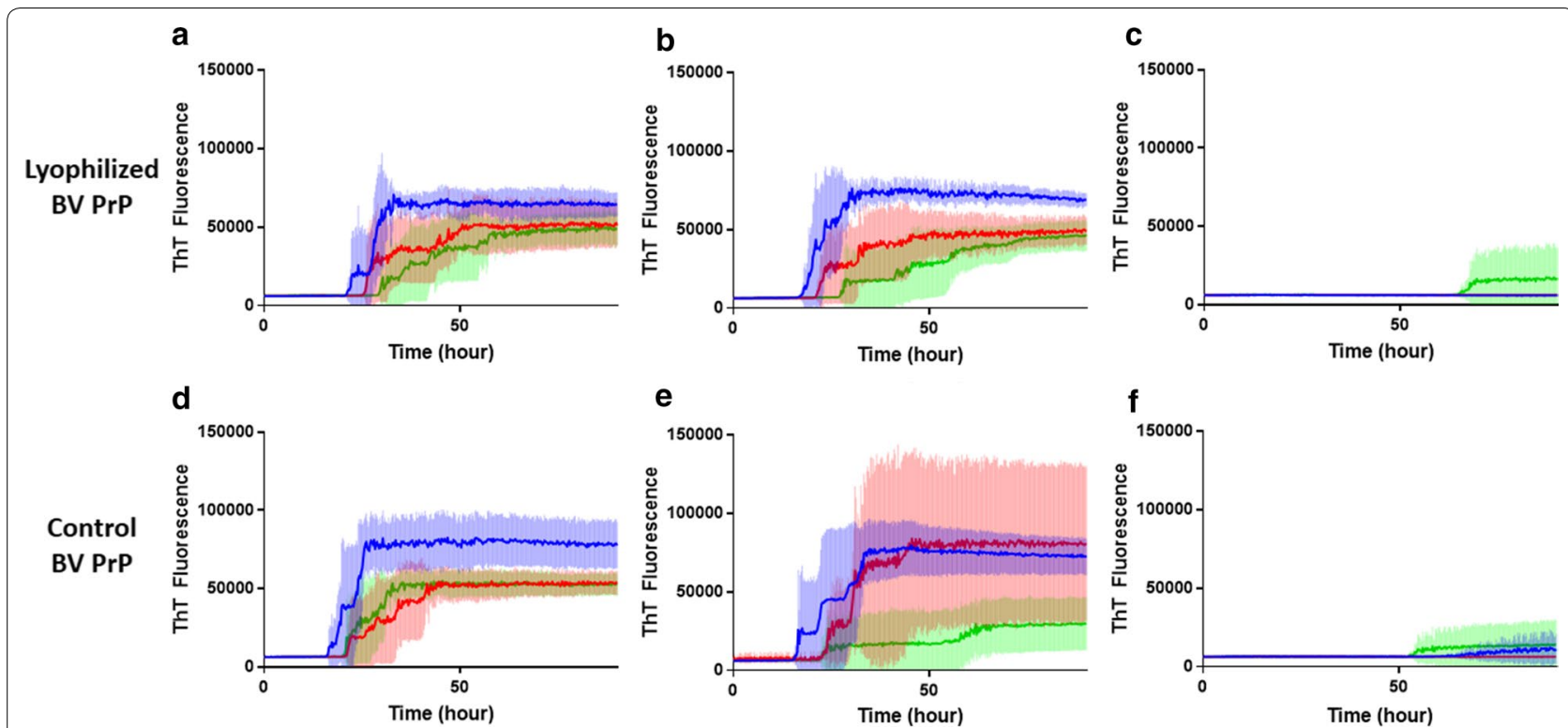

Fig. 3 Comparison of seeding activity of RT-QulC reactions using $\mathbf{a}-\mathbf{c}$ resolubilized after lyophilization and $\mathbf{d}-\mathbf{f}$ freshly prepared BV rPrP as substrates. RT-QulC reactions were seeded with $10^{-3}$ (blue), $10^{-4}$ (red), and $10^{-5}$ (green) dilutions of two scrapie-infected sheep brains from 2 different scrapie positive sheep $\mathbf{a}$ and $\mathbf{d}$ are the same infected sheep, $\mathbf{b}$ and $\mathbf{e}$ are the same infected sheep and a negative control (uninfected sheep, $\mathbf{c}$ and $\mathbf{f}$ ) brain homogenates with the addition of $0.001 \%$ of SDS. Shown are the average ThT fluorescence readings (thick lines) with standard deviations (thin lines) determined from all replicates (four replicate reactions per brain dilution). The results of $\mathbf{a}, \mathbf{b}, \mathbf{d}$ and $\mathbf{e}$ all meet the criteria to be determined positive by RT-QulC as defined in the methods

By no means is this the first use of lyophilization and resolubilization of rPrP. Lyophilized recombinant prion protein has been previously included as part of $\mathrm{rPrP}$ preparation protocols, although when included it is typically followed by a resolubilization step including either chemical or thermal unfolding and subsequent refolding prior to use [15-18]. However, this is the first study, to which the authors are aware, that has utilized lyophilized rPrP as a substrate for RT-QuIC.

RT-QuIC has been used for an efficient tool to detect $\mathrm{PrP}^{\mathrm{Sc}}$ from humans and animals [9-11, 31-34], even in the presymptomatic stage of disease [35-37]. RT-QuIC has also been shown to be potentially useful for studies such as drug prescreening, prion strain discrimination, and screening for prion contamination [38]. A variety of substrates have been applied for RT-QuIC reactions including hamster (23-231 and 90-231) [31], hamstersheep chimera [39], mouse (23-231) [25], sheep (25-234) [22], human (23-231) [32], deer (24-234) [31], and elk (24-234) [40, 41]. Of the studied PrP sequences, bank vole prion protein appears to be the most practical substrate for diagnostic settings due to its reputation as a universal substrate for RT-QuIC [14]. Also, BV rPrP supports detection of different seeding activity and distinct products of RT-QuIC reactions for different types of human $\operatorname{PrP} \mathrm{P}^{\mathrm{Sc}}[14]$.
RT-QuIC has been shown to be sensitive and specific for a number of applications in TSE diagnostics. However, the need for a continued source of freshly prepared and purified $\mathrm{rPrP}$ is a limitation of the technique. To address this, researchers have aliquoted large preparations of protein and stored them at $-80{ }^{\circ} \mathrm{C}$ with a claimed storage life on the order of 6 months [23]. While the limit of storage lifetime was not established in this study, lyophilized rPrP should extend storage lifetime at temperatures below and above freezing relative to storage in aqueous solution.

In this study, we show that lyophilized BV rPrP can be applied for RT-QuIC reactions to detect $\mathrm{PrP}^{\mathrm{Sc}}$ in scrapieinfected clinical samples by amplification of fibril content present in a scrapie positive brain homogenate. The effect of lyophilization on BV rPrP was determined to be negligible by comparison to freshly prepared protein solution with regard to secondary protein structure from $\mathrm{CD}$ spectra, melting temperature from thermal denaturation curves, and seeding activity from RT-QuIC Across these 3 features we found no significant change as a result of lyophilization. Therefore, lyophilization is a suitable means to preserve BV rPrP for shipping and storage with the ultimate goal of efficient use of RT-QuIC for laboratory research and diagnostic applications. 


\section{Limitations}

The data presented here shows that the use of lyophilized BV rPrP is feasible with little or no change to the results found for freshly prepared BV rPrP. However, there are limitations to this study. Namely we did not fully determine the storage shelf life of lyophilized BV rPrP nor did we assess the storage of BV rPrP over a variety of temperatures, rather we limited our evaluation to $4{ }^{\circ} \mathrm{C}$ to approximate cold room storage or shipping on wet ice and a time limit consistent with storage of freshly prepared BV $\mathrm{rPrP}$ to facilitate direct comparison. While determining the time and temperature limits would undoubtedly be important for development of a distributable test kit this study provides an important proof of principle assessment of the applicability of including lyophilization in the preparation of $\mathrm{BV} \mathrm{rPrP}$ for the purposes of RT-QuIC, an important step toward development of a distributable test kit.

\begin{abstract}
Abbreviations
RT-QuIC: real time quaking induced conversion; TSEs: transmissible spongiform encephalopathies; $\operatorname{PrPC}^{\mathrm{C}}$ : cellular prion protein; $\mathrm{Pr}^{\mathrm{Sc}}$ : pathogenic prion protein; CWD: chronic wasting disease; CJD: Creutzfeldt-Jakob disease; EIA: enzyme immunoassay; PMCA: protein misfolding cyclic amplification; rPrP: recombinant prion protein; BV: bank vole; SCJD: sporadic CJD; ThT: thioflavin T; CD: circular dichroism.
\end{abstract}

\section{Authors' contributions}

Conceptualization: EMN, SH. Formal analysis: SH. Investigation: SH. Methodology: EMN SH TT SLM. Resources: EMN. Supervision: EMN. Writing original draft: SH EMN. Writing review and editing: SH EMN. All authors read and approved final the manuscript.

\section{Acknowledgements \\ Not applicable.}

\section{Competing interests}

The authors declare that they have no competing interests.

\section{Availability of data and materials}

The datasets used and/or analysed during the current study are in the manuscript and any additional details will be made available from the corresponding author on reasonable request.

\section{Consent for publication}

Not applicable.

\section{Disclaimer}

Mention of trade names or commercial products in this publication is solely for the purpose of providing specific information and does not imply recommendation or endorsement by the U.S. Department of Agriculture. USDA is an equal opportunity provider and employer.

Ethics approval and consent to participate Not applicable.

\section{Funding}

This research was funded in its entirety by congressionally appropriated funds to the United States Department of Agriculture, Agriculture Research Service. The funder of the work did not influence study design, data collection and analysis, decision to publish, and preparation of the manuscript.

\section{Publisher's Note}

Springer Nature remains neutral with regard to jurisdictional claims in published maps and institutional affiliations.

Received: 3 October 2018 Accepted: 4 December 2018

Published online: 14 December 2018

\section{References}

1. Prusiner SB. Prions. Proc Natl Acad Sci USA. 1998;95(23):13363-83.

2. Weissmann C. The Ninth Datta lecture. Molecular biology of transmissible spongiform encephalopathies. FEBS Lett. 1996;389(1):3-11.

3. Prusiner SB. Novel proteinaceous infectious particles cause scrapie. Science. 1982:216(4542):136-44.

4. Van Everbroeck B, Pals P, Martin JJ, Cras P. Antigen retrieval in prion protein immunohistochemistry. J Histochem Cytochem. 1999;47(11):1465-70.

5. Peretz D, Williamson RA, Matsunaga Y, Serban H, Pinilla C, Bastidas $\mathrm{RB}$, et al. A conformational transition at the $\mathrm{N}$ terminus of the prion protein features in formation of the scrapie isoform. J Mol Biol. 1997;273(3):614-22

6. Soto C, Saborio GP, Anderes L. Cyclic amplification of protein misfolding: application to prion-related disorders and beyond. Trends Neurosci. 2002;25(8):390-4.

7. Soto C, Anderes L, Suardi S, Cardone F, Castilla J, Frossard MJ, et al. Pre-symptomatic detection of prions by cyclic amplification of protein misfolding. FEBS Lett. 2005;579(3):638-42.

8. Saa P, Castilla J, Soto C. Cyclic amplification of protein misfolding and aggregation. Methods Mol Biol. 2005;299:53-65.

9. Atarashi R, Satoh K, Sano K, Fuse T, Yamaguchi N, Ishibashi D, et al. Ultrasensitive human prion detection in cerebrospinal fluid by real-time quaking-induced conversion. Nat Med. 2011;17(2):175-8.

10. Atarashi R, Sano K, Satoh K, Nishida N. Real-time quaking-induced conversion: a highly sensitive assay for prion detection. Prion. 2011;5(3):150-3.

11. McGuire LI, Peden AH, Orru CD, Wilham JM, Appleford NE, Mallinson $\mathrm{G}$, et al. Real time quaking-induced conversion analysis of cerebrospinal fluid in sporadic Creutzfeldt-Jakob disease. Ann Neurol. 2012;72(2):278-85

12. Piening N, Nonno R, Di Bari M, Walter S, Windl O, Agrimi U, et al. Conversion efficiency of bank vole prion protein in vitro is determined by residues 155 and 170, but does not correlate with the high susceptibility of bank voles to sheep scrapie in vivo. J Biol Chem. 2006;281(14):9373-84.

13. Watts JC, Giles K, Stohr J, Oehler A, Bhardwaj S, Grillo SK, et al. Spontaneous generation of rapidly transmissible prions in transgenic mice expressing wild-type bank vole prion protein. Proc Natl Acad Sci USA 2012;109(9):3498-503.

14. Orru CD, Groveman BR, Raymond LD, Hughson AG, Nonno R, Zou W, et al. Bank Vole prion protein as an apparently universal substrate for RTQulC-based detection and discrimination of prion strains. PLoS Pathog. 2015;11(6):e1004983.

15. Moulick R, Das R, Udgaonkar JB. Partially unfolded forms of the prion protein populated under misfolding-promoting conditions: characterization by hydrogen exchange mass spectrometry and NMR. J Biol Chem. 2015;290(42):25227-40

16. Makarava N, Baskakov IV. The same primary structure of the prion protein yields two distinct self-propagating states. J Biol Chem. 2008;283(23):15988-96.

17. Ladner-Keay CL, Griffith BJ, Wishart DS. Shaking alone induces de novo conversion of recombinant prion proteins to beta-sheet rich oligomers and fibrils. PLoS ONE. 2014;9(6):e98753.

18. Andrievskaia O, McRae H, Elmgren C, Huang H, Balachandran A, Nielsen K. Generation of antibodies against bovine recombinant prion protein in various strains of mice. Clin Vaccine Immunol. 2006;13(1):98-105.

19. Vrentas CE, Greenlee JJ, Tatum TL, Nicholson EM. Relationships between $\operatorname{PrP}^{S C}$ stability and incubation time for United States scrapie isolates in a natural host system. PLOS ONE. 2012;7(8):e43060.

20. Moore SJ, Smith JD, Greenlee MH, Nicholson EM, Richt JA, Greenlee JJ. Comparison of two US sheep scrapie isolates supports identification as separate strains. Vet Pathol. 2016;53(6):1187-96. 
21. Vrentas CE, Onstot S, Nicholson EM. A comparative analysis of rapid methods for purification and refolding of recombinant bovine prion protein. Protein Expr Purif. 2012;82(2):380-8.

22. Dassanayake RP, Orru CD, Hughson AG, Caughey B, Graca T, Zhuang D, et al. Sensitive and specific detection of classical scrapie prions in the brains of goats by real-time quaking-induced conversion. J Gen Virol. 2016;97(3):803-12.

23. Cheng K, Sloan A, Avery KM, Coulthart M, Carpenter M, Knox JD. Exploring physical and chemical factors influencing the properties of recombinant prion protein and the real-time quaking-induced conversion (RT-QulC) assay. PLoS ONE. 2014;9(1):e84812.

24. Orru CD, Hughson AG, Groveman BR, Campbell KJ, Anson KJ, Manca M, et al. Factors that improve RT-QulC detection of prion seeding activity. Viruses. 2016;8(5):140. https://doi.org/10.3390/v8050140.

25. Masujin K, Orru CD, Miyazawa K, Groveman BR, Raymond LD, Hughson $A G$, et al. Detection of atypical H-type bovine spongiform encephalopathy and discrimination of bovine prion strains by real-time quakinginduced conversion. J Clin Microbiol. 2016;54(3):676-86.

26. Orru CD, Favole A, Corona C, Mazza M, Manca M, Groveman BR, et al. Detection and discrimination of classical and atypical L-type bovine spongiform encephalopathy by real-time quaking-induced conversion. J Clin Microbiol. 2015;53(4):1115-20.

27. Hwang S, Greenlee JJ, Nicholson EM. Use of bovine recombinant prion protein and real-time quaking-induced conversion to detect cattle transmissible mink encephalopathy prions and discriminate classical and atypical L- and H-Type bovine spongiform encephalopathy. PLOS ONE. 2017;12(2):e0172391.

28. Orru CD, Groveman BR, Hughson AG, Zanusso G, Coulthart MB, Caughey B. Rapid and sensitive RT-QulC detection of human Creutzfeldt-Jakob disease using cerebrospinal fluid. MBio. 2015;6(1):e02451-14. https://doi. org/10.1128/mBio.02451-14

29. Orru CD, Bongianni M, Tonoli G, Ferrari S, Hughson AG, Groveman BR, et al. A test for Creutzfeldt-Jakob disease using nasal brushings. N Engl J Med. 2014;371(6):519-29.

30. Swint L, Robertson AD. Thermodynamics of unfolding for turkey ovomucoid third domain: thermal and chemical denaturation. Protein Sci. 1993;2(12):2037-49
31. Wilham JM, Orru CD, Bessen RA, Atarashi R, Sano K, Race B, et al. Rapid end-point quantitation of prion seeding activity with sensitivity comparable to bioassays. PLoS Pathog. 2010;6(12):e1001217.

32. Peden AH, McGuire LI, Appleford NE, Mallinson G, Wilham JM, Orru CD, et al. Sensitive and specific detection of sporadic Creutzfeldt-Jakob disease brain prion protein using real-time quaking-induced conversion. J Gen Virol. 2012;93(Pt 2):438-49.

33. Orru CD, Wilham JM, Vascellari S, Hughson AG, Caughey B. New generation QulC assays for prion seeding activity. Prion. 2012;6(2):147-52.

34. Elder AM, Henderson DM, Nalls AV, Wilham JM, Caughey BW, Hoover EA, et al. In vitro detection of prionemia in TSE-infected cervids and hamsters. PLOS ONE. 2013;8(11):e80203.

35. Cheng YC, Hannaoui S, John TR, Dudas S, Czub S, Gilch S. Early and non-invasive detection of chronic wasting disease prions in elk feces by real-time quaking induced conversion. PLoS ONE. 2016;11(11):e0166187.

36. Hwang S, West Greenlee MH, Balkema-Buschmann A, Groschup MH, Nicholson EM, Greenlee JJ. Real-time quaking-induced conversion detection of bovine spongiform encephalopathy prions in a subclinical steer. Front Vet Sci. 2017;4:242.

37. Haley NJ, Henderson DM, Wycoff S, Tennant J, Hoover EA, Love D, et al. Chronic wasting disease management in ranched elk using rectal biopsy testing. Prion. 2018;12(2):93-108.

38. Schmitz M, Cramm M, Llorens F, Muller-Cramm D, Collins S, Atarashi R, et al. The real-time quaking-induced conversion assay for detection of human prion disease and study of other protein misfolding diseases. Nat Protoc. 2016;11(11):2233-42.

39. Henderson DM, Manca M, Haley NJ, Denkers ND, Nalls AV, Mathiason CK, et al. Rapid antemortem detection of CWD prions in deer saliva. PLoS ONE. 2013;8(9):e74377.

40. Samorodnitsky D, Nicholson EM. Differential effects of divalent cations on elk prion protein fibril formation and stability. Prion. 2018;12(1):63-71.

41. Moore SJ, Vrentas CE, Hwang S, West Greenlee MH, Nicholson EM, Greenlee JJ. Pathologic and biochemical characterization of PrP(Sc) from elk with PRNP polymorphisms at codon 132 after experimental infection with the chronic wasting disease agent. BMC Vet Res. 2018;14(1):80.
Ready to submit your research? Choose BMC and benefit from:

- fast, convenient online submission

- thorough peer review by experienced researchers in your field

- rapid publication on acceptance

- support for research data, including large and complex data types

- gold Open Access which fosters wider collaboration and increased citations

- maximum visibility for your research: over 100M website views per year

At $\mathrm{BMC}$, research is always in progress.

Learn more biomedcentral.com/submissions 